\title{
El microrrelato en Hispanoamérica: dos hitos para una historiografía / nuevas prácticas de escritura y de lectura
}

\author{
José Luis Fernández Pérez*
}

\begin{abstract}
Resumen
El presente trabajo intenta establecer algunos puntos de inflexión en el desarrollo del microrrelato en nuestro continente, considerando el aporte de productores y antologadores como agentes de mediación cultural. Para ello, el artículo se detiene a examinar el trabajo antológico de 1953 de Jorge Luis Borges y Adolfo Bioy Casares Cuentos breves y extraordinarios, así como una producción autorial de Juan José Arreola -la serie textual "Prosodia", integrada en Confabulario total(1941-1961)- como hitos decisivos en la construcción genérica del microcuento, cuya impronta ha marcado de manera decisiva a este formato narrativo como modelo de escritura y de recepción.
\end{abstract}

Palabras clave: Microrrelato (microcuento), Construcción genérica, escritura fragmentaria, rol de antologador, intertextualidad, pragmática literaria

\begin{abstract}
The article aims to establish some turning point in the development of short-short-story in our continent, considering the contribution of producers and anthologators as agents of social mediation. To this end, the article examines the anhologic work of Jorge Luis Borges of 1953 and Adolfo Bioy Casares Cuentos breves y extraordinarios, along with an authoring work of Juan José Arreola -the textual series Prosodia intregrated into Confabulario total (1941-1961)- as crucial highlight in the generic construction of the short-short-story, where imprint has profoundly marked this narrative format as model of witting and reception.
\end{abstract}

Keywords: Short-short-story, generic construction, fragmentary writing, anthologator role, literary pragmatic

* José Luis Fernández Pérez académico de la Universidad Católica Silva Henríquez. Doctor (c) en Literatura, Pontificia Universidad Católica de Chile. jlfernan@ucsh.cl 


\section{Territorio preliminar}

La aparición de un nuevo formato y soporte expresivo al interior de un sistema literario es un proceso que se va configurando, muchas veces lenta e imperceptiblemente, con la participación de diversos agentes mediadores (autores, recopiladores, editores y críticos, entre otros), quienes van movilizando fuerzas de renovación al tiempo que paulatinamente van construyendo/modificando pautas de lectura y normas de valoración en una escena cultural ${ }^{1}$. Retroactivamente, es posible, entonces, plantearse la necesidad de ir puntualizando algunos hitos que pudieran representar enclaves relevantes para la consolidación del microcuento en la narrativa hispanoamericana ${ }^{2}$, puntos de inflexión que bien pudieron delinear nuevas prácticas literarias que han ido emergiendo asociadas a su despunte y desarrollo. A ello pretende contribuir esta breve reflexión que deseo compartir.

Desde Rubén Darío y Alfonso Reyes hasta la prosa dispersa de nuestro Vicente Huidobro, pasando por el imprescindible Julio Torri, Macedonio Fernández y algunas propuestas de Oliverio Girondo, es conocido el rol de adelantados que han jugado algunos autores del modernismo tardío y de las vanguardias históricas en la exploración estética de las posibilidades narrativas del fragmento y la plasmación de los primeros microcuentos, tal como la ha sistematizado ya David Lagmanovich en su completísimo trabajo El microrrelato. Teoría e historia (2006). No obstante, esta modalidad genérica alcanza, como sabemos, una legitimación tardía en nuestro medio (pensemos que en estas latitudes el formato logra una divulgación algo más masiva desde la escritura de resistencia de los años 70 y 80; en tanto la academia solo se decide a concederle mayores espacios de reconocimiento a partir de los 90). A pesar de que el historial del microcuento hispanoamericano cuenta ya con una vasta tradición de cultores y promotores, los hitos de desarrollo son aún poco difundidos. Por lo mismo, en una visión sumaria, teniendo como base a Lagmanovich, podríamos enunciar aquí una cronología de los hitos de producción del microcuento hispanoamericano, trazando una periodización dispuesta así:

- Etapa de los precursores / 1917-1949 (lo fragmentario como experimentación y/o recolección residual): Torri, Lugones, Fernández, Anderson Imbert.

- Etapa de los arquitectos / 1950-1960 (de la intuición minimalista al programa de escritura): Arreola, Borges, Monterroso.

1 Esta mirada integradora del hecho literario como un objeto comunicativo complejo se asienta en algunas premisas compartidas tanto por los empiristas alemanes liderados por Siegfried Schmidt como por la Teoría de los Polisistemas, que sigue los postulados del israelí Itamar Even Zohar. Desde estos enfoques, el fenómeno literario se considera como un proceso sociohistórico que dinamiza diversas prácticas sociales en torno a su quehacer, relevando el importante rol de los distintos actores que participan del sistema cultural.

2 Precisamente en este campo disciplinar se inscribe la investigación que he desarrollado en la Pontificia Universidad Católica de Chile como parte de mi tesis doctoral en curso. El trabajo es dirigido por el Dr. Danilo Santos y cuenta con la cotutoría del Dr. Juan Armando Epple (Universidad de Oregon) y el financiamiento de CONICyT. 
- Etapa de la consolidación de una tradición / 1960-1970 (de las nuevas búsquedas expresivas y la intertextualidad programática): Cortázar, Denevi, Monterroso.

- Etapa de expansiones y rupturas / 1970-1985 (de los discursos en crisis y el microrrelato en complicidad con el testimonio): Alcalde, Peri Rossi, Barros, Valenzuela, Galeano, Muñoz Valenzuela, Jiménez Emán.

- Etapa de las nuevas voces / 1985-2006 (las hibridaciones genéricas y el desmarque de los padres): Shua, Britto García, Guedea.

En lo que sigue, intento levantar dos hitos, los que, si bien pueden ser de tránsito, históricamente intersticiales, a mi juicio desempeñan un papel digno de revisarse en la configuración de un modelo textual que con el tiempo ha devenido en modelo de lectura. Estos nos pueden servir como claves para dar cuenta de algunas transformaciones en el complejo proceso de validación cultural que el microcuento ha experimentado en la escena hispanoamericana de los últimos 50 años.

\section{Hallando un lugar: dos hitos, dos visiones}

En efecto, desde mediados del siglo XX comienzan a circular algunos libros que contribuyen de un modo particular a este proceso, tornándose poco a poco en referencia ineludible. Entre ellos merecen nuestra atención dos producciones: la conocida antología Cuentos breves y extraordinarios (1953), de Jorge Luis Borges y Adolfo Bioy Casares, junto a la publicación de Confabulario total (1941-1961) (1962), de Juan José Arreola, en especial la nueva serie textual introducida bajo el título de "Prosodia". Según creo, estas producciones movilizan prácticas literarias -es decir, de escritura y de lectura- que permiten entrever la apertura de nuevos espacios de codificación para el reconocimiento artístico de la narrativa breve, desplazando a esta definitivamente desde los márgenes de la nota residual o del experimentalismo vanguardista de circulación restringida hacia territorios de mayor legitimación estética y social.

Con respecto a la publicación de Borges y Bioy Casares, puede llamar su atención que se postule un lugar tan primordial en una historiografía del microcuento hispanoamericano para un objeto antológico. Pues bien, creo que con este volumen se funda un modo de relacionarse con los textos narrativos hasta entonces sin precedentes en la región. El libro, de 1953, bien puede considerarse como la primera compilación de microcuentos (al menos en el ámbito hispanoparlante), dada la brevísima extensión de los textos que la componen, la autonomía y valor artístico que a estos se les asigna, el rescate explícito de su narratividad y el curioso lente de recolección que sustenta el volumen, guiado por un hedonismo aparentemente caprichoso y la validación de las operaciones de recorte que organizan su caótica trama.

Una suerte de enciclopedia de variadísima filiación cultural con cierta disposición aleatoria -noción por lo demás nada extraña en el imaginario de 
Borges-, parece orientar los criterios de selección que se dejan entrever en el prólogo firmado por los antologadores:

este libro quiere proponer al lector algunos ejemplos del género (narrativo), ya referentes a sucesos imaginarios, ya a sucesos históricos. Hemos interrogado, para ello, textos de diversas naciones y de diversas épocas, sin omitir las antiguas y generosas fuentes orientales. La anécdota, la parábola y el relato hallan aquí hospitalidad, a condición de ser breves. (Borges y Bioy Casares, 1953).

En el caso de Cuentos breves y extraordinarios, la opción programática de poner en escena al fragmento como módulo autosuficiente -esto es, autovalidado textual y artísticamente-, no es en absoluto azarosa. La preferencia sistemática por el ingenio de lo breve y su fuerza de impacto aquí se vuelven norma, a riesgo de contravenir ciertos supuestos comunicacionales inscritos en el intercambio simbólico del fenómeno literario moderno. Como ya se insinúa en el prólogo, varios de los textos que conforman el volumen han sido recortados de sus macrotextos de origen: incluso varios de ellos han sido titulados, careciendo de estos paratextos de apertura en su presentación original. Esta acción recolectora tiende a reformular las reglas que tradicionalmente han guiado las relaciones entre la instancia autorial y los agentes mediadores, como es el caso de los antologadores.

De lo anterior se deriva una transformación de los circuitos culturales por los que transitará el microcuento, lo que resultará más o menos decisivo en el futuro desarrollo de la minificción en Hispanoamérica, como es la incorporación de las operaciones de recorte como modelo de lectura y/o reescritura. Sin que todavía se manipulen aún los cuerpos textuales de un original mediante estrategias paródicas u otros juegos intertextuales, la acción recontextualizadora emprendida por los antologadores permite avizorar un nuevo pacto contractual entre el autor y el lector, dando pie para nuevos circuitos de reproducción cultural. Importantes antologías posteriores asumen este procedimiento como una pauta modélica: el ya canónico Libro de la imaginación (1976), del mexicano Edmundo Valadés y la más contemporánea Antología del cuento breve y oculto (2001), de los argentinos Raúl Brasca y Luis Chitarroni se hacen eco de esta práctica, que se asume como operación co-autorial, transfiriendo poder compositivo a los antologadores en el concepto y en los hechos. Desde esta perspectiva, son estos mediadores culturales, guiados por su sensibilidad para auscultar y pesquisar historias escondidas, al decir de Violeta Rojo (2004), los llamados a definir aquello que goza de autonomía de sentido y valor literario, prescindiendo de la voluntad autorial, dando lugar a un incierto y amplísimo campo de virtualidad narrativa.

Creo que este proyecto antológico ha sido concebido y modelado gracias al advenimiento de una nueva forma de relacionarse con los textos de mayor extensión, sean estos novelas, ensayos o crónicas; asimismo, se han puesto en marcha nuevos protocolos para vincularse con la tradición, contribuyendo 
oblicuamente a modificar la actitud -irreverente y productivamente creadoracon la que mediadores y futuros autores se acercan al canon. Con ello no solo se pone al fragmento escena con pretensión de renovada totalidad, sino que, sobre todo, se incorpora al gesto de relectura como una actividad particularmente próxima a la escritura, dimensión que será particularmente prolífica en la obra de eminentes constructores del género, como Augusto Monterroso y Marco Denevi.

En la medida en que las operaciones de recorte -esto es, la acción modélica de antologar fragmentos descontextualizados para revivirlos bajo nuevas dimensiones y nominaciones- se vuelven más recurrentes desde los 70 para adelante en el campo de minificción hispanoamericana, Laura Pollastri (2004) y Lauro Zavala (2005) han llegado a postular la emergencia de una estrategia de lectura fragmentaria como práctica predilecta entre varios antologadores. Este "nuevo modo de armar", que por cierto conlleva una renovada concepción de las reglas que conducen el quehacer antológico, abre las puertas para que la acción compiladora asuma otras propiedades en el campo de la comunicación literaria. Como lúcidamente señala Pollastri (2004: 226):

[aquí se] acusa la capacidad del antólogo para establecer lecturas: el fragmento propuesto ahora como totalidad recorre el camino inverso al de producir el fragmento como tal. Entre la instancia de producción moderna de estos textos y el reciclamiento desviado, posmoderno de los antólogos se organiza un corpus de lecturas pervertidas y archivos saqueados. No es lo mismo un microrrelato producido como tal, que un texto leído como microrrelato.

En consonancia con lo que ya algunos estudiosos han reparado, leer y recolectar textos es una práctica literaria que se vuelve muy próxima a la reescritura. Así ocurre con Borges y Bioy Casares. Después de todo, no puede pasar inadvertido que más tarde Bioy Casares, mediante Guirnalda con amores (1958), y sobre todo el Borges de El hacedor (1960), cultivaron el microcuento como formato predilecto con singular maestría y convicción. Podemos conjeturar, entonces, que la (re)lectura precedió a la escritura como acción modélica en la vinculación que estos autores mantuvieron con la nueva forma genérica que se abría en su horizonte.

En lo que respecta a la serie textual "Prosodia", integrada en Confabulario total (1941-1961), a mi parecer, con esta producción Arreola refuerza su intuición sobre las posibilidades literarias del formato breve, al tiempo que retoma las experimentaciones de hibridación genérica iniciadas por Torri décadas atrás, con lo cual se empieza a prefigurar lo que más tarde se conocería como el carácter proteico del microcuento, siguiendo a Violeta Rojo.

En efecto, la serie textual referida destaca por la yuxtaposición de segmentos de disímil filiación, cuya organicidad parece solo recaer sobre el registro elegíaco que le sirve de fondo. Fragmentos apocalípticos, apuntes autobiográficos de visión degradada, montajes pesadillescos, alegorías de inspiración medieval, 
remates de tono sentencioso y elaboraciones paródicas de factura fantástica, componen un conjunto heterogéneo sin más. Paradójicamente, al parecer éste basa una dimensión importante de su identidad en una aparente dispersión; no obstante, bajo ella respira la libertad formal que lo anima. Aquí conviven formaciones textuales que posibilitan la coexistencia de protosecuencias narrativas con descripciones de un tratamiento preponderantemente lírico, a las cuales en no pocas ocasiones siguen breves notas de comentario con registros aforísticos que se vinculan con la íntima reflexividad del ensayo y el espíritu lúdico heredado de las vanguardias, todo casi siempre insuflado de contenido humor.

El programa escritural futuro de Arreola se caracteriza por una creciente ocupación formal sobre las posibilidades de la construcción miniaturista. El gesto autorial de producir una obra sustentada exclusivamente sobre el fragmento, como ocurrirá en 1963 con la novela La feria (texto que un sector de la crítica considera más bien como una serie de microcuentos integrados), irá confiriendo un nuevo estatuto para el cuento breve, formato que en el curso de los años 60 comienza a situarse como una escritura reconocible, con un patrón compositivo y estrategia comunicativa más o menos definidos.

El modelo se presentaba capaz de solventar una propuesta estética modular fundada en la brevedad como principio organizador, tanto del proceso creativo como del tipo de efecto perseguido en el transcurso de su recepción. Por de pronto, diremos que con Juan José Arreola, la brevedad comienza a edificarse, en tanto escala de representación autoimpuesta, como un principio constructivo que emerge tan definitorio como determinante. Sobre esta condición se afianza un modo particular de narrar -el cual se consagrará paradigmáticamente más tarde con el dinosaurio monterrosiano-: Esto supone no tan solo un modo específico de concebir y elaborar la materia narrativa, sino que, también, una manera peculiar de llevar adelante la acción de leer historias de ficción.

Lo que en el concierto de la narrativa hispanoamericana se iría perfilando como una poética de la ultrabrevedad, se vincula entonces con cierta noción preconcebida del dialogismo cultural y cognitivo que la instancia autorial requiere movilizar en el transcurso de la lectura con tal de asegurar una recepción exitosa. Así opera esto en "Flash" (1955), uno de los microcuentos de factura más contemporánea del volumen comentado, el cual el crítico mexicano Lauro Zavala sindicaría como relato posmoderno, dada la relectura irónica de la cultura que compromete su recepción:

Londres, 26 de noviembre (AP).- Un sabio demente, cuyo nombre no ha sido revelado, colocó anoche un Absorsor del tamaño de una ratonera en la salida de un túnel. El tren fue vanamente esperado en la estación de llegada. Los hombres de ciencia se afligen ante el objeto dramático, que no pesa más que antes, y que contiene todos los vagones del expreso de Dover y el apretado número de las víctimas.

Ante la consternación general, el Parlamento ha hecho declaraciones en el sentido de que el Absorsor se halla en etapa experimental. Consiste en una 
cápsula de hidrógeno, en la cual se efectúa un vacío atómico. Fue planeado originalmente por Sir Acheson Beal como arma pacífica, destinada a anular los efectos de las explosiones nucleares.

Este microcuento fue uno de los primeros que impulsó una intertextualidad discursiva incorporando/problematizando la escritura de los mass media: tal vez ello explique su notable actualidad a más de 50 años de su creación. En efecto, el hipotexto no corresponde a un episodio clásico del canon occidental, como ya se venía ensayando desde Torri, sino a una nota de prensa breve y escueta, destinada a impactar más que a informar. Desde el título paragenérico se sugiere al lector que estamos ante una operación de trasvestismo discursivo. Al fogonazo del título sigue la datación y la sigla de una seudoagencia informativa que corroboran la fidelidad inicial al modelo. Sin embargo, a poco andar la hiperbolización del desastre referido y las incógnitas de una realidad crecientemente alterada, van dando forma a un tratamiento periodístico en clave de sarcasmo, lo que obliga rápidamente a ajustar el protocolo de recepción a otro sistema de verosimilitud: aquí se impone la coexistencia de lo previsible con el absurdo, lo que lleva, necesariamente, a una autorregulación de los códigos que orientan nuestra lectura. El empleo de oxímoron, unido al mantenimiento de ambigüedades impropias del texto noticioso, terminan pervirtiendo el modelo original, parodiándolo desde una retórica sostenida en la paradoja y la desmesura, desconstruyendo el repertorio discursivo mimético que el lector mantenía inicialmente como pauta de lectura informativa, sustituyéndolo por una codificación más próxima a la tradición del absurdo kafkiano. Las explicaciones de autoridad, seriamente fundadas en consideraciones científicas, no hacen sino aumentar el desconcierto y la sensación de indolencia ante la desgracia humana comprometida en el atentado, desplazando el foco de interés hacia la descripción del aparato causante de la tragedia, cinismo mediante. La distancia irónica que domina el cierre permite concluir con una insólita referencia a las buenas intenciones del mentor del arma, con lo cual el absurdo se lleva al paroxismo.

La lectura activa de este microcuento asume cierta familiaridad con el modelo sujeto a parodia, a saber: las notas de prensa interesadas en las tragedias de fácil impacto y rápida digestión y/o la transcripción mecánica de comunicados de prensa (de impecable pirámide invertida), que escamotean conflictos y ocultan responsabilidades. Una lectura exitosa -placentera al decir de Barthes- solo sería viable en la medida en que el lector se empodere de los códigos que le permitan entablar la complicidad anhelada por una escritura que le propone reírse de lo trágico como estrategia de neutralización para conjurar/contener las angustias compartidas. Aquí la elaboración ficcional en régimen fantástico y el juego de travestismo discursivo operarían como un cuidadoso artificio para mantener en el subtexto la crítica sobre la realidad denunciada, en donde el blanco ya no estaría centrado en la referencia de la anécdota, sino más bien en los pliegues de la situación discursiva develada en el funcionamiento del modelo imitado. Aquí, por cierto, ficción y compromiso terminan por darse la mano. 
De este modo, el incipiente modelo del microcuento hispanoamericano no solo es caracterizable desde sus dimensiones e invariantes intratextuales. Para ello se requiere además atender a la particular vocación comunicativa que lo impulsa, orientada de manera especial hacia el logro de ciertos efectos por conseguir en la lectura (a veces humorísticos, a veces dilatorio, por lo general jugando con las incertidumbres del lector en contacto con el micromundo que se le presenta y se le deshace ante su mirada y su imaginación), objetivos estéticos que tal vez vuelven exigible la escala de representación de máxima condensación.

Por consiguiente, se aprecia que a través del despunte de la minificción de Arreola, no solo se afianza la posibilidad de desarrollar una extensa obra narrativa sobre la base del formato breve, sino que se pone en evidencia que las complejidades compositivas y comunicativas derivadas de la ultrabrevedad suponen adentrarse en los alcances pragmáticos de este programa escritural. Estos universos ficcionales contraídos, muchas veces replegados sobre sus omisiones o ambigüedades, otorgan al lector responsabilidades cruciales en la instancia de la recepción, la que por momentos se vuelve particularmente dialógica, por cuanto la completación de información y la activación de supuestos culturales movilizan una diégesis prefigurada desde sugerencias y abismos.

\section{Coda: hacia una nueva cartografía}

La mirada sobre el binomio de producciones aquí comentadas puede contribuir sobre un mayor grado de comprensión sobre el cuadro general del microcuento hispanoamericano, toda vez que sobre éste se trazan algunas distinciones y complementariedades que pueden resultar decisivas para la configuración historiográfica del género. De un lado, la relevancia de las obras de autor; del otro, la importancia de los objetos antológicos; por una parte, la apuesta por una retórica híbrida y fronteriza; por otra, la insistente auscultación sobre diversas formas de narratividad solapada.

Por de pronto, a modo de visión sumaria sobre la ruta y campo sobre el cual ha transitado el microrrelato hispanoamericano, digamos que, apenas estas entrañables "otras cosas" comenzaron a circular y luego a proliferar, se echó a andar un imprevisible proceso de relecturas y re-elaboraciones: estas "otras cosas" fueron instalando sus espacios de afinidad, adquiriendo un nombre (una etiqueta, un rótulo provisional, equívoco o múltiple) y paulatinamente algunos actores las hicieron propias. Desde la creación, la lectura y distintas acciones de divulgación, les fueron concediendo un lugar en sus iniciativas y proyectos, al tiempo que asumían, sin darse cuenta tal vez, roles de intermediarios y agentes de transformación: editores de pequeñas revistas abrieron espacios para la escritura de estos "artefactos" mientras recuperaban a algún maestro que servía de inspiración y modelo (Monterroso, Arreola, Borges, el mismo Cortázar cronopiano); algunos escritores iniciados comenzaron a desarrollar su praxis 
creativa a partir de estos modelos e hicieron escuela a través de incipientes talleres, multiplicando los potenciales productores y ensayando variaciones sobre el paradigma consagrado.

Desde los años '80, diversas iniciativas antológicas recopilan este material disperso (contamos con el encomiable trabajo de Juan Armando Epple entre nosotros), en tanto sendos prólogos se esmeran por contextualizar y validar la nueva forma narrativa, dirigiéndose alternativamente a la academia y al lector común, inaugurando con ello una tradición metatextual que va perfilando y regulando la acción de futuros productores y receptores. En el intertanto, los nuevos soportes electrónicos y una incipiente divulgación masiva a través de textos escolares y concursos, da cuenta de un proceso de circulación material y simbólica que va definiendo un locus: una instancia de intercambio simbólico que va, poco a poco, instalando a los microcuentos como objetos literarios de genuino valor estético, dignos de interés en la escena cultural y académica.

Lo anterior es un primer intento por describir el complejo proceso, a un tiempo material y simbólico, de circulación y asimilación de ciertos textos literarios y de las valoraciones, protocolos y prácticas sociales que se van generando a partir de su incorporación a un sistema y a una historia. El hecho literario, así concebido, comprende mecanismos y estructuras institucionales que van delineando la cartografía sociocultural de los textos mediante el concurso de diversos agentes que conforman una comunidad letrada. Una historiografía del microrrelato hispanoamericano debiera integrar, entonces, las dinámicas de consumo, difusión y crítica que lo han ido perfilando como un género narrativo particular, haciendo dialogar las convenciones de producción con la recepción, intentando recomponer las pautas de apreciación que la tradición metatextual ha ido instalando sobre ellos.

\section{Bibliografía}

Arreola, Juan José (1952). Confabulario, México D.F.: Fondo de Cultura Económica.

Arreola, Juan José (1962). Confabulario total (1941-1961), México D.F.: Fondo de Cultura Económica.

Arreola, Juan José (1963). La feria, México D.F.: Joaquín Mortiz.

Bioy Casares, Adolfo (1959). Guirnalda de amores, Buenos Aires: Emecé.

Borges, Jorge Luis y Adolfo Bioy Casares (1953). Cuentos breves y extraordinarios, Buenos Aires, Emecé.

Borges, Jorge Luis (1960). El hacedor, Buenos Aires: Emecé.

Brasca, Raúl y Luis Chitarroni, comp. (2001). Antología del cuento breve y oculto, Buenos Aires, Sudamericana.

Cáceres Milenes, Andrés y Eddie Morales Piña, edit. (2005) Asedios a un nueva categoría textual: el microrrelato (Actas del III Congreso Internacional 
de Minificción/2004), Valparaíso: Ediciones de la Facultad de Humanidades de la Universidad de Playa Ancha.

Chico Rico, Francisco, ed. (1994). La ciencia empírica de la literatura. Conceptos, métodos, consecuencias, Madrid: Verbum.

Epple, Juan Armando (1990). Brevísima relación. Antología del micro-cuento hispanoamericano, Santiago: Mosquito editores.

Epple, Juan Armando (2004). "La minificción y la crítica", en Noguerol Jiménez, Francisca, ed. (2004). Escritos disconformes. Nuevos modelos de lectura, Salamanca: Ediciones Universidad de Salamanca, pp. 15-24.

Fernández Pérez, José Luis (2005). "Hacia la conformación de una matriz genérica para el microcuento hispanoamericano" en Literatura y Lingüistica $\mathrm{N}^{\circ} 16$, Santiago: Ediciones de la Universidad Católica Silva Henríquez, pp.107-134.

Lagmanovich, David (2006), El microrrelato. Teoría e historia, Madrid: Menos Cuarto ediciones.

Larrea, María Isabel (2005). "La recepción de los microcuentos con historia", en Cáceres Milenes, Andrés y Eddie Morales Piña, edit. (2005). Asedios a un nueva categoría textual: el microrrelato, Valparaíso: Ediciones de la Facultad de Humanidades de la Universidad de Playa Ancha (pp.193-202)

Jandová, Jarmila y Emil Volek, eds. (2000). Signo, función y valor. Estética y semiótica del arte de Jan Mukarovsky, Bogotá: Plaza y Janés Editores.

Noguerol Jiménez, Francisca, ed. (2004). Escritos disconformes. Nuevos modelos de lectura (Actas del II Congreso Internacional de Minificción), Salamanca: Ediciones Universidad de Salamanca.

Pollastri, Laura (2005). "Piezas de un rompecabezas: ficción breve y fragmento en la literatura hispanoamericana”, en Cáceres Milenes, Andrés y Eddie Morales Piña, edit. (2005) Asedios a un nueva categoría textual: el microrrelato, Valparaíso: Ediciones de la Facultad de Humanidades de la Universidad de Playa Ancha (pp. 219232).

Rojo, Violeta (1996). Breve manual para reconocer minicuentos, Caracas: Equinoccio y Fundarte.

Rojo, Violeta (2004). "De las antologías de minicuento como instrumentos para la definición teórica", en Noguerol Jiménez, Francisca, ed. (2004). Escritos disconformes. Nuevos modelos de lectura, Salamanca: Ediciones Universidad de Salamanca, (pp. 131-133).

Zavala, Lauro (2004). Paseos por el cuento mexicano contemporáneo, México D.F.: Nueva Imagen.

Zavala, Lauro (2005). La minificción bajo el microscopio, Bogotá: Universidad Pedagógica Nacional.

VV AA, (2005). Teorías de la historia literaria, Madrid: Arco Libros. 